Prolonged PR interval, first-degree heart block and adverse cardiovascular outcomes:

\title{
A systematic review and meta-analysis
}

Running title: Heart block and adverse cardiovascular outcomes

Chun Shing Kwok MBBS MSc ${ }^{1,2}$, Muhammad Rashid MBBS ${ }^{1,3}$, Rhys Beynon MD $^{2}$, Diane

Barker $\mathrm{MD}^{2}$, Ashish Patwala $\mathrm{MD}^{2}$, Adrian Morley-Davies $\mathrm{MB}$ BCh $\mathrm{PhD}^{2}$, Duwarakan Satchithananda $\mathrm{MBChB}^{2}$, James Nolan $\mathrm{MD}^{1,2}$, Phyo K Myint $\mathrm{MD}^{4}$, Iain Buchan MB ChB $\mathrm{PhD}^{5}$, Yoon K Loke $\mathrm{MD}^{6 *}$, Mamas A Mamas BMBCh $\mathrm{PhD}^{1,2,5^{*}}$

1. Keele Cardiovascular Research Group, Institutes of Science and Technology in Medicine and Primary Care and Health Sciences, UK.

2. Royal Stoke University Hospital, Stoke on Trent, UK.

3. St. Helens \& Knowsley Teaching Hospital (NHS) Trust, Whiston Hospital, Prescot, UK.

4. The Institute of Applied Health Sciences, University of Aberdeen, Aberdeen, UK.

5. Farr Institute, University of Manchester, Manchester, UK.

6. Norwich Medical School, University of East Anglia, Norwich, UK.

*Joint senior authors who contributed equally

\section{Corresponding Author:}

Dr. Chun Shing Kwok

Cardiology Registrar and Academic Clinical Fellow in Cardiology

Keele Cardiovascular Research Group, Institute for Science \& Technology in Medicine, Keele University, Guy Hilton Research Centre,

Thornburrow Drive, Hartshill, Stoke-on-Trent, United Kingdom, ST4 7QB

Email: shingkwok@doctors.org.uk

Telephone: +44 (0) $1782671653 \quad$ Fax: +44 (0)178 2674467

Keywords: bradyarrhythmias, meta-analysis, atrial fibrillation, heart failure

Word count: 3,146 
The Corresponding Author has the right to grant on behalf of all authors and does grant on behalf of all authors, an exclusive licence (or non exclusive for government employees) on a worldwide basis to the BMJ Publishing Group Ltd and its Licensees to permit this article (if accepted) to be published in HEART editions and any other BMJPGL products to exploit all subsidiary rights. 


\section{Abstract}

Objective: First-degree atrioventricular block is frequently encountered in clinical practice and is generally considered a benign process. However, there is emerging evidence that prolonged PR interval may be associated with adverse outcomes. This study aims to determine if prolonged PR interval is associated with adverse cardiovascular outcomes and mortality.

Methods: We searched MEDLINE and EMBASE for studies that evaluated clinical outcomes associated with prolonged and normal PR intervals. Relevant studies were pooled using random effects meta-analysis for risk of mortality, cardiovascular mortality, heart failure, coronary heart disease, atrial fibrillation and stroke or transient ischemic attack. Sensitivity analyses were performed considering the population type and use of adjustments.

Results: Our search yielded 14 studies that were undertaken between 1972 and 2011 with 400,750 participants. Among the studies that adjusted for potential confounders, the pooled results suggest an increased risk of mortality with prolonged PR interval RR 1.24 95\%CI 1.02-1.51, 5 studies. Prolonged PR interval was associated with significant risk of heart failure or left ventricular dysfunction (RR 1.39 95\%CI 1.18-1.65, 3 studies) and atrial fibrillation (RR 1.45 95\%CI 1.23-1.71, 8 studies) but not cardiovascular mortality, coronary heart disease or myocardial infarction or stroke or TIA. Similar observations were recorded when limited to studies of first-degree heart block.

Conclusions: Data from observational studies suggests a possible association between prolonged PR interval and significant increases in atrial fibrillation, heart failure and mortality. Future prospective studies are needed to confirm the relationships reported, consider possible mechanisms and define the optimal monitoring strategy for such patients. 


\section{Key Questions:}

\section{What is already known about this subject?}

- First-degree atrioventricular block, defined as PR interval greater than $200 \mathrm{~ms}$, is frequently encountered in clinical practice.

- In patients who are incidentally found to have first-degree heart block, current expert advice suggests that this poses little risk and is not associated with significant symptoms and no specific treatment is required.

\section{What does this study add?}

- Our review of 14 studies with over 400,000 participants suggests that prolonged PR interval was associated with increased risk of mortality, heart failure and atrial fibrillation.

- Similar significant increases in mortality, heart failure and atrial fibrillation were observed when limited to studies of first-degree heart block.

\section{How might this impact on clinical practice?}

- Physicians should not automatically dismiss first degree heart block as a benign condition.

- Contrary to current expert advice, our results suggest that closer monitoring may be warranted for future events, although effective risk reduction strategies still need to be developed. 


\section{Introduction}

First-degree atrioventricular block $\left(1^{\circ} \mathrm{HB}\right)$, defined as PR interval greater than 200 ms, is frequently encountered in clinical practice and considered a benign process.[1,2] The PR interval reflects the propagation of electrical impulses from the onset of atrial depolarization to the beginning of ventricular depolarization. Although the prevalence of PR prolongation is relatively rare amongst the younger population $(1 \%$ among those age $<60$ years) it becomes much more common after the age of $\geq 60$ years, with prevalence rising to

6\%.[3] Whilst it has been suggested that enhanced vagal tone underlies the etiology of $1^{\circ} \mathrm{HB}$ in young people, organic heart disease is more prevalent in older subjects and may be linked to myocardial conduction system fibrosis and conduction abnormalities in these groups of patients.[4] In patients who are incidentally found to have $1^{\circ} \mathrm{HB}$, current expert advice suggests that $1^{\circ} \mathrm{HB}$ poses little risk, is not associated with significant symptoms and no specific treatment is required.[5-7]

The ACC/AHA/HRS 2008 guidelines suggest that permanent pacemaker is not indicated for asymptomatic $1^{\circ} \mathrm{HB}$ except for neuromuscular disease such as myotonic dystrophy[8] whilst the European Society of Cardiology recommends with class IIa and level C evidence that permanent pacemaker should be considered for patients with persistent symptoms similar to those of pacemaker syndrome and attributable to $1^{\circ} \mathrm{HB}$ ( $\mathrm{PR}>0.3 \mathrm{~s}$ ).[9]

However, the current conservative approach to $1^{\circ} \mathrm{HB}$ may have been based on older studies with major methodological limitations.[10,11] Judgments regarding the benign nature of $1^{\circ} \mathrm{HB}$ and prolonged $\mathrm{PR}$ interval may be erroneous because of small sample sizes, inadequate follow up to capture sufficient events, confounding, lack of adjustment for baseline characteristics or poor outcome ascertainment. Several more recent studies have drawn association between prolonged PR interval and cardiovascular outcomes but there are clearly conflicting viewpoints in the existing literature.[12-17] The only previous systematic 
review evaluated the risk of atrial fibrillation with prolonged PR interval but this review did not look at other outcomes such as mortality and cardiovascular diseases.[18] As there are several recent publications that have studied the association between prolonged PR interval / $1^{\circ} \mathrm{HB}$, we have re-assessed the relationship between prolonged PR interval / $1^{\circ} \mathrm{HB}$ and $\mathrm{CV}$ outcomes. We conduct a systematic review and meta-analysis to evaluate the association between prolonged $\mathrm{PR}$ interval or $1^{\circ} \mathrm{HB}$ and mortality, atrial fibrillation, heart failure, coronary heart disease and stroke. 


\section{Methods}

\section{Eligibility criteria}

We selected studies that evaluated adverse outcomes in patients with and without $1^{\circ} \mathrm{HB}$ or prolonged PR interval on electrocardiogram. The adverse outcomes of interest were mortality, cardiovascular mortality, heart failure or left ventricular dysfunction, coronary heart disease or myocardial infarction, atrial fibrillation, stroke or transient ischemic attack, progression of heart block or need for pacemaker insertion. While $1^{\circ} \mathrm{HB}$ is clearly defined as $\geq 200 \mathrm{~ms}$, we chose to also include studies that focused on "prolonged PR interval", in which this was variably defined by individual authors as anywhere between $>196 \mathrm{~ms}$ to $>220 \mathrm{~ms}$. Included studies had to have two groups (one with longer PR interval), which would allow risk estimates to be calculated. There was no restriction based on study design, cohort type or language of study report. However, we excluded studies of patients with specific cardiac pathologies that were uncommon (such as aortic stenosis, sinus nodal dysfunction, heart failure) or had received intervention (angiography or cardiac resynchronization therapy) from the main analysis.

Search strategy

We searched MEDLINE and EMBASE using OVID SP with no date or language restriction in May 2015. The exact search terms were: (first degree atrioventricular heart block or prolonged PR interval or PR prolongation or first-degree atrioventricular block) AND (atrial fibrillation or myocardial infarction or acute coronary syndrome or ischemic heart disease or ischemic heart disease or coronary heart disease or coronary artery disease or stroke or cerebrovascular disease or cerebrovascular accident or heart failure or cardiac failure or mortality or death). We checked the bibliography of relevant studies and reviews for additional studies that met the inclusion criteria. 


\section{Study selection and data extraction}

Two reviewers (CSK, MR) screened all titles and abstracts retrieved from the search for studies that met the inclusion criteria. The full manuscript of studies that potentially met the inclusion criteria were reviewed and the final decision to include or exclude studies were made with two other reviewers (YKL, MAM). Independent double extractions were performed by two reviewers (CSK, MR) and data was collected on study design, year, country, number of participants, mean age, \% male, participant inclusion criteria, definition of prolonged PR interval, outcomes evaluated, timing of assessment and results.

Risk of bias assessment

Quality assessment of the studies was conducted with consideration of ascertainment of PR prolongation, outcome ascertainment, loss to follow up and use of adjustments for medication, cardiovascular disease and other adjustments.

Data analysis

We used RevMan 5.3.5 (Nordic Cochrane Centre) to conduct random effects metaanalysis using the inverse variance method for pooling log risk ratios (RR). We used random effects because the studies were conducted in a wide range of settings in different populations, hence the need to take heterogeneity into account for the pooled effect estimate. Where possible, we chose to pool adjusted risk estimates from primary studies and when this data was not available raw data was used to calculate unadjusted risk estimates. The primary outcome was all-cause mortality and analysis was performed considering adjusted and unadjusted group separately. Subgroup analysis was performed considering whether the population evaluated was a general population or subjects with cardiovascular disease. We also performed sensitivity analysis by including only studies which evaluated $1^{\circ} \mathrm{HB}(>200 \mathrm{~ms}$ or $\geq 200 \mathrm{~ms}$ ) excluding studies which did not adjust for a) medications and b) cardiovascular disease. 


\section{Results}

Description of studies included in analysis

The progress of study selection is shown in Supplementary Figure 1. Out of the 879 studies retrieved from the search, 26 studies were relevant but 12 studies were excluded from the analysis (Supplementary Table 1). A total of 14 studies [4,10-17,20-24] were included: 12 general population studies, 1 cohort with coronary heart disease[20] and 1 cohort with hypertension.[16]

Table 1 shows the baseline characteristics of the participants. There were a total of 400,750 participants amongst the 14 studies (11 prospective cohort studies [4,10-13,17,2024], 3 retrospective cohort studies[14-16]). The mean age from the 10 studies was 56 years and the percentage of participants that were male ranged from $18 \%$ to $100 \%$.. The studies were undertaken between 1972 and 2011 and were undertaken in Finland, USA, Norway, Japan, Korea, Australia and Denmark. Prevalence of prolonged PR interval ranged from 2\% to $14 \%$ across 7 studies and the mean prevalence was $7 \%$. 
Table 1: Study design and participant characteristics

\begin{tabular}{|c|c|c|c|c|c|}
\hline Study ID & Study design; year; country & $\begin{array}{l}\text { No. of } \\
\text { participants }\end{array}$ & $\begin{array}{l}\text { Mean age, } \\
\text { median } \\
\text { age or age } \\
\text { range }\end{array}$ & \% Male & Participant inclusion criteria \\
\hline Cheng 2009 & $\begin{array}{l}\text { Prospective cohort study; } 1968 \\
\text { to 2007; USA. }\end{array}$ & 7,575 & $\begin{array}{l}\text { Mean } 47 \\
\text { years. }\end{array}$ & $46 \%$ & $\begin{array}{l}\text { Participants were community-based individuals from } \\
\text { the Framingham Heart Study. }\end{array}$ \\
\hline $\begin{array}{l}\text { Erikssen } \\
1984\end{array}$ & $\begin{array}{l}\text { Prospective cohort study; } \\
\text { enrolment 1972-1975; } \\
\text { Norway. }\end{array}$ & 1,635 & $\begin{array}{l}40-59 \\
\text { years at } \\
\text { baseline. }\end{array}$ & $100 \%$ & $\begin{array}{l}\text { Participants were 'apparently healthy' men aged 40-59 } \\
\text { years free of coronary heart disease. }\end{array}$ \\
\hline $\begin{array}{l}\text { Hisamatsu } \\
2015\end{array}$ & $\begin{array}{l}\text { Prospective cohort study; } 1980 \\
\text { to 2009; Japan. }\end{array}$ & 9,051 & $\begin{array}{l}\text { Mean } 50 \\
\text { years. }\end{array}$ & $44 \%$ & $\begin{array}{l}\text { Participants were community dwellers, aged 30-95 } \\
\text { years from } 300 \text { randomly selected areas throughout } \\
\text { Japan. }\end{array}$ \\
\hline $\begin{array}{l}\text { Magnani } \\
2013\end{array}$ & $\begin{array}{l}\text { Prospective cohort study; } 1997 \\
\text { to 2011; USA. }\end{array}$ & 2,722 & $\begin{array}{l}\text { Mean } 74 \\
\text { years. }\end{array}$ & $48 \%$. & $\begin{array}{l}\text { Participants were a random sampling of community- } \\
\text { dwelling older patients (age } 70-79 \text { years) free of } \\
\text { disability or functional limitation from the Health, } \\
\text { Aging and Body Composition Study. }\end{array}$ \\
\hline Nielsen 2013 & $\begin{array}{l}\text { Prospective cohort study; } 2001 \\
\text { to 2010; Denmark. }\end{array}$ & 288,181 & $\begin{array}{l}\text { Median } 54 \\
\text { years. }\end{array}$ & $45 \%$. & $\begin{array}{l}\text { Participants were from primary care who had } \geq 1 \text { ECG } \\
\text { recorded at the Copenhagen General Practitioners' } \\
\text { Laboratory. }\end{array}$ \\
\hline
\end{tabular}




\begin{tabular}{|l|l|l|l|l|l|}
\hline Perez 2009 & $\begin{array}{l}\text { Retrospective cohort study; } \\
\text { Mar 1987 to Jul 2000; USA. }\end{array}$ & 42,751 & $\begin{array}{l}\text { Mean 56 } \\
\text { years. }\end{array}$ & $90 \%$. & $\begin{array}{l}\text { Participants had initial ECG between Mar 1987 and Jul } \\
\text { 2000. Indications for ECG and background disease - } \\
\text { not known, but patients with known AF were excluded } \\
\text { from study. }\end{array}$ \\
\hline Rajala 1985 & $\begin{array}{l}\text { Prospective cohort study; Jan } \\
1977 \text { to Dec 1982; Finland. }\end{array}$ & 674 & $\begin{array}{l}\text { Age }>85 \\
\text { years. }\end{array}$ & $18 \%$. & $\begin{array}{l}\text { Participants were 85 years or older community-based } \\
\text { sample living in the city of Tampere in } 1977 .\end{array}$ \\
\hline $\begin{array}{l}\text { Soliman } \\
2009\end{array}$ & $\begin{array}{l}\text { Retrospective cohort study; } \\
1987 \text { to 1998; USA. }\end{array}$ & 15,429 & $\begin{array}{l}\text { Mean 54.2 } \\
\text { years. }\end{array}$ & $45 \%$. & $\begin{array}{l}\text { Participants were from 4 US communities aged 45 to } \\
\text { 64 years in the Atherosclerosis Risk in Communities } \\
\text { study. }\end{array}$ \\
\hline $\begin{array}{l}\text { Soliman } \\
2014\end{array}$ & $\begin{array}{l}\text { Prospective cohort study; 1988 } \\
\text { to Dec 2006; USA. }\end{array}$ & 7,501 & $\begin{array}{l}\text { Mean 59.3 } \\
\text { years. }\end{array}$ & $\begin{array}{l}\text { Participants were civilian noninstitutionalized US } \\
\text { population in the NHANES study. }\end{array}$ \\
\hline Uhm 2013 & $\begin{array}{l}\text { Retrospective cohort study; } \\
\text { Unclear; Korea. }\end{array}$ & 3,816 & $\begin{array}{l}\text { Mean } 61.0 \\
\text { years. }\end{array}$ & $47.2 \%$. & $\begin{array}{l}\text { Participants were age }>18 \text { years with hypertension and } \\
\text { sinus rhythm on first ECG. }\end{array}$ \\
\hline
\end{tabular}




\section{Risk of bias in studies}

The evaluation of the quality of studies is shown in Supplementary Table 2. All studies used ECG to ascertain PR prolongation but only eight studies reported the leads used to measure PR interval. A variety of methods were used to ascertain outcomes including data from registries, telephone contact and medical records. Seven studies reported some degree of loss to follow up which ranged from $1 \%$ to $9 \%$. Aside from two studies, all the studies used multivariate analysis to adjust for potential confounders ( 9 adjusted for medications, 7 adjusted for cardiovascular disease and 8 adjusted for heart rate). Two studies with unadjusted data were considered to be at high risk of bias.[10,11]

\section{Description of included studies}

Table 2 shows the description of reference group, outcomes evaluated, timing of assessment and results. The definition of PR prolongation varied across the studies from $>196 \mathrm{~ms}$ to $>220 \mathrm{~ms}$ and follow up for outcomes amongst studies was between 5 to 24 years. Seven studies used the $200 \mathrm{~ms}$ as the cut off and were included in the $1^{\circ} \mathrm{HB}$ analysis.

\section{Risk of adverse outcomes with prolonged PR interval}

The risk of mortality with prolonged PR interval is shown in Figure 1a). There were a total of seven studies in the analysis and five of which adjusted for potential confounders. The pooled estimate of adjusted studies (based on a total of 14,454 deaths/37,634 participants) suggests a significant increase in mortality with prolonged PR interval (RR 1.24 95\% CI 1.02-1.51). The crude event rate for the two unadjusted studies was 547 deaths/2,331 participants (38\%). The pooled estimate from unadjusted analyses (that are at high risk of bias) showed that prolonged PR interval was associated with reduced overall mortality (RR 0.72 95\% CI 0.55-0.99). 
The risk of other adverse outcomes with prolonged PR interval is shown in Figure 1b). Prolonged PR interval was associated with significant risk of heart failure or left ventricular dysfunction (RR 1.39 95\%CI 1.18-1.65, 3 studies, event rate 2,389/17,323, 14\%) and atrial fibrillation (RR 1.45 95\%CI 1.23-1.71, 8 studies, event rate 15,616/375,526, 4\%) but not cardiovascular mortality, coronary heart disease or myocardial infarction or stroke or TIA.

Additional analysis was performed considering all studies including patients with previous coronary heart disease and hypertension and adjustments for medication and cardiovascular disease (Table 3). We observed similar significant increases in adjusted mortality, heart failure or LV dysfunction and atrial fibrillation in these additional analyses. 
Table 3: Summary of meta-analysis results

A) General population studies

\begin{tabular}{|l|l|l|l|}
\hline Adverse outcome & \multicolumn{3}{|l|}{ General population studies } \\
\cline { 2 - 4 } & $\begin{array}{l}\text { No. of } \\
\text { studies }\end{array}$ & Events/Total & Risk ratio (95\% CI) \\
\hline $\begin{array}{l}\text { All mortality } \\
\begin{array}{l}\text { Adjusted only } \\
\text { Unadjusted only }\end{array}\end{array}$ & 5 & $\begin{array}{l}14,454 / 37,634 \\
15,001 / 39,965\end{array}$ & $\begin{array}{l}1.24(1.02-1.51) \\
0.73(0.55-0.99)\end{array}$ \\
\hline $\begin{array}{l}\text { Cardiovascular } \\
\text { mortality }\end{array}$ & 2 & $3,086 / 21,471$ & $0.93(0.74-1.17)$ \\
\hline $\begin{array}{l}\text { Heart failure or LV } \\
\text { dysfunction }\end{array}$ & 3 & $2,389 / 17,323$ & $1.39(1.18-1.65)$ \\
\hline CHD or MI & 4 & $4,006 / 26,896$ & $1.08(0.85-1.36)$ \\
\hline Atrial fibrillation & 8 & $15,616 / 37,526$ & $1.45(1.23-1.71)$ \\
\hline Stroke or TIA & 4 & & $1.13(0.82-1.56)$ \\
\hline
\end{tabular}

B) All studies (including studies of patients with CAD)

\begin{tabular}{|l|l|l|l|}
\hline \multirow{2}{*}{ Adverse outcome } & \multicolumn{3}{|l|}{ All studies (including studies of patients with CAD) } \\
\cline { 2 - 4 } & $\begin{array}{l}\text { No. of } \\
\text { studies }\end{array}$ & Events/Total & Risk ratio (95\% CI) \\
\hline $\begin{array}{l}\text { All mortality } \\
\begin{array}{l}\text { Adjusted only } \\
\text { Unadjusted only }\end{array}\end{array}$ & 7 & $\begin{array}{l}14,739 / 38,572 \\
547 / 2,331\end{array}$ & $\begin{array}{l}1.23(1.01-1.49) \\
0.73(0.55-0.99)\end{array}$ \\
\hline $\begin{array}{l}\text { Cardiovascular } \\
\text { mortality }\end{array}$ & 2 & $3,153 / 22,409$ & $1.14(0.73-1.76)$ \\
\hline $\begin{array}{l}\text { Heart failure or LV } \\
\text { dysfunction }\end{array}$ & 4 & $2,512 / 18,261$ & $1.51(1.22-1.88)$ \\
\hline CHD or MI & 4 & $4,006 / 26,896$ & $1.08(0.85-1.36)$ \\
\hline Atrial fibrillation & 8 & $15,616 / 375,526$ & $1.45(1.23-1.71)$ \\
\hline Stroke or TIA & 4 & $3,258 / 40,690$ & $1.13(0.82-1.56)$ \\
\hline
\end{tabular}

C) Only inclusion of studies that adjusted for medications

\begin{tabular}{|l|l|l|l|}
\hline \multirow{2}{*}{ Adverse outcome } & \multicolumn{3}{|l|}{ Only inclusion of studies that adjusted for medications } \\
\cline { 2 - 4 } & $\begin{array}{l}\text { No. of } \\
\text { studies }\end{array}$ & Events/Total & Risk ratio (95\% CI) \\
\hline $\begin{array}{l}\text { All mortality } \\
\text { Adjusted only }\end{array}$ & 7 & $14,739 / 48,209$ & $1.23(1.01-1.49)$ \\
\hline $\begin{array}{l}\text { Cardiovascular } \\
\text { mortality }\end{array}$ & 3 & $3,116 / 20,774$ & $1.19(0.75-1.88)$ \\
\hline $\begin{array}{l}\text { Heart failure or LV } \\
\text { dysfunction }\end{array}$ & 4 & $2,512 / 18,261$ & $1.51(1.22-1.88)$ \\
\hline CHD or MI & 1 & $3,539 / 10,785$ & $0.97(0.77-1.22)$ \\
\hline Atrial fibrillation & 6 & $14,449 / 317,346$ & $1.50(1.15-1.96)$ \\
\hline Stroke or TIA & 2 & $2,418 / 19,836$ & $1.00(0.59-1.70)$ \\
\hline
\end{tabular}

D) Only inclusion of studies that adjusted for CVD

\begin{tabular}{|l|l|l|l|}
\hline \multirow{2}{*}{ Adverse outcome } & \multicolumn{3}{|l|}{ Only inclusion of studies that adjusted for CVD } \\
\cline { 2 - 4 } & $\begin{array}{l}\text { No. of } \\
\text { studies }\end{array}$ & Events/Total & Risk ratio (95\% CI) \\
\hline $\begin{array}{l}\text { All mortality } \\
\text { Adjusted only }\end{array}$ & 6 & $11,470 / 39,158$ & $1.26(1.02-1.56)$ \\
\hline
\end{tabular}




\begin{tabular}{|l|l|l|l|}
\hline $\begin{array}{l}\text { Cardiovascular } \\
\text { mortality }\end{array}$ & 2 & $2,015 / 11,723$ & $1.42(0.59-3.46)$ \\
\hline $\begin{array}{l}\text { Heart failure or LV } \\
\text { dysfunction }\end{array}$ & 4 & $2,512 / 18,261$ & $1.51(1.22-1.88)$ \\
\hline CHD or MI & 1 & $3,539 / 10,785$ & $0.97(0.77-1.22)$ \\
\hline Atrial fibrillation & 5 & $14,106 / 313,079$ & $1.53(1.14-2.04)$ \\
\hline Stroke or TIA & 1 & $1,927 / 10,785$ & $1.23(0.93-1.63)$ \\
\hline
\end{tabular}

$\mathrm{CAD}=$ coronary artery disease, $\mathrm{CVD}=$ cardiovascular disease, $\mathrm{CHD}=$ coronary heart disease, $\mathrm{MI}=$ myocardial infarction, $\mathrm{TIA}=$ transient ischemic attack 
In addition, Cheng et al was the only study to report two important outcomes associated with $1^{\circ} \mathrm{HB}$ which were need for pacemaker insertion and progression of heart block.

The results for adverse outcomes with prolonged PR interval using the cutoffs for $1^{\circ} \mathrm{HB}$ are shown in Figure 2. Similar to prolonged PR interval there were significant increases in mortality (RR 1.31 95\% CI 1.18-1.46), heart failure (RR 1.39 95\% CI 1.18-1.65) and atrial fibrillation (RR 1.47 (1.18-1.83) but not cardiovascular mortality, coronary heart disease or stroke. 


\section{Discussion}

Our results suggest that prolonged PR interval and $1^{\circ} \mathrm{HB}$ are not benign conditions and are associated with increased mortality, heart failure and atrial fibrillation. Physicians should not therefore consider $1^{\circ} \mathrm{HB}$ as a benign condition. Contrary to current expert advice, our results suggest that closer monitoring may be warranted for future events, although effective risk reduction strategies still need to be developed.

The mechanism that underlies the association between $1^{\circ} \mathrm{HB}$ and adverse cardiovascular outcomes and mortality is unclear. Cheng et al suggests that chronic PR prolongation could be a precursor to more severe degrees of conduction block.[12] This is supported by their findings that there was a significant increase in need for pacemaker and progression of heart block with $1^{\circ} \mathrm{HB}$.[12] Further evidence supporting the progression of heart block is provided by a study of 446 participants with acute myocardial infarction which found that one third of those who developed first degree heart block progressed to third degree heart block.[25] Progression of heart block may relate to underlying causes of atrioventricular block and progression of these pathologies which include primary or idiopathic (generally considered as fibrosis in origin), and secondary to conditions such as coronary heart disease, calcification, inflammation, infiltrative diseases and neuromuscular disorders.[26] Myocardial fibrosis is known to slow conduction and increase vulnerability to arrhythmia.[27] Fibrosis of the conduction tissue is a dynamic process which can accumulate with repeated insults secondary to these pathological processes. These accumulated changes over time may explain the initial manifestation of first degree heart and progression to higher degree of heart block and mortality.

Cheng et al also suggest that prolongation of PR interval may be a marker of other cardiovascular changes associated with worse prognosis such as advanced physiological age.[12] Electrophysiological studies which have demonstrated that atrial conduction velocity 
in both atria declines and the atria becomes more refractory with increasing age; this may explain age related increase in prevalence of atrial fibrillation.[28,29] Aging can also manifest as calcification or fibrosis of the cardiac skeleton.[12] In addition, age is known to be associated with increased risk of mortality and cardiovascular disease such as ischemic heart disease and heart failure. We observed a greater mean age in patients in the prolonged PR interval group compared to normal PR interval group in several studies.[4,12,13,17,20] However, the majority of the included studies adjusted for age which suggests that the increased risk of cardiovascular events with $1^{\circ} \mathrm{HB}$ cannot be explained by ageing alone.

Crisel et al suggest that $1^{\circ} \mathrm{HB}$ may be a marker of diffuse ischemic heart disease.[20] However, our findings do not support this as prolonged PR interval does not increase coronary heart disease, stroke and cardiovascular mortality which are related to atherosclerosis and vascular pathology. Magnani et al suggest that prolongation of PR has been associated with obesity, waist circumference and components of metabolic syndrome which are also associated with incident heart failure.[23] They also suggest that hypertension may be a confounder that causes heart failure with both preserved and compromised systolic function and cause elevated intra-cardiac pressures and secondary altered atrial electrical function.[23] In addition, prolonged PR interval may unmask existing cardiac pathology such as heart failure.

Our results support the findings of existing studies. Cheng et al conducted a metaanalysis of six cohort studies and reported an increased risk of atrial fibrillation with $1^{\circ}$ HB.[18] There are two additional studies in our review, Perez et al[14] and Uhm et al[16] and both of these studies suggest an increased risk of atrial fibrillation with $1^{\circ} \mathrm{HB}$. We build upon this review by including the other outcomes mortality, cardiovascular mortality, heart failure, coronary heart disease and stroke. 
We identified three older studies suggesting no increase in mortality with AV block or first degree heart block but these studies did not provide specific statistical analyses and results that met our criteria for inclusion in the meta-analysis. The study by Kitchin et al, evaluated mortality rates of 487 random adults with and without AV block.[30] Mortality was lower in the AV block group compared to control group (21\% vs $24 \%$ ) but the study did not report specifically on first degree heart block. The study by Rose et al, evaluated coronary heart disease death at 5 years with different ECG abnormalities.[31] However, confidence intervals for the adjusted rates were not reported. The Copenhagen City Heart study of 19,662 adults stated that there was no difference between the normal ECG group and those with AV conduction defects but did not quantify outcome data.[32] We believe that there is insufficient granularity in data from these older studies for us to make any robust interpretation on cardiovascular or mortality risk. Moreover, the population and management of cardiovascular disease has changed substantially since these older studies, so it is unclear if these results are generalizable to current practice.

The long follow up in many of these studies is an important consideration in the interpretation of the findings. This may suggest that event rates may be very low so a long follow up time is need to capture enough events to show a difference. Because $1^{\circ} \mathrm{HB}$ can be asymptomatic it is unclear exactly how long patients have had heart block for prior to inclusion in the study. This represents a problem because all of the studies are observational in nature. However, the long follow up time between heart block and adverse events may provide a window for which patients can be identified and management can be implemented to reduce risk of cardiovascular pathology.

While first degree heart block is generally considered to be PR interval greater than 200 ms the upper limit of the "normal" PR interval is necessarily arbitrary.[3] In the current study, prolonged PR interval ranged from 196 to 220 ms. 
An important question generated from these findings is the management strategy that should be undertaken if $1^{\circ} \mathrm{HB}$ is incidentally found. Guidelines recommend against pacemaker insertion unless patients are symptomatic and according to ESC guidelines the PR interval is $>300 \mathrm{~ms} .[7,9]$ The options include following up these patients and if so how frequently (probably unrealistic to see them yearly, perhaps every 3 years or 5 years). Furthermore, it is unclear whether formal cardiovascular risk assessment should be undertaken as recommended for high risk groups at risk of future cardiovascular events such as those with established cardiovascular disease, diabetes mellitus and renal disease.[33]

While we were able to show significant associations between prolonged PR interval and certain adverse outcomes (e.g. mortality, atrial fibrillation and heart failure) the pooled effect sizes are small and there are only a limited number of studies for each outcome. Consequently, the findings may be affected by the possibility of residual confounding. Therefore, findings of this current systematic review should be interpreted as evidence to raise the hypothesis that prolonged PR interval may be a risk factor for several adverse cardiac outcomes. These results do support further studies to assess the association of prolonged PR interval and adverse cardiovascular outcome but at present we cannot definitely conclude that the association is causal.

We observed differences in study results and this may be attributed to dissimilarity among the include studies in terms of geographic locations, baseline cardiovascular risk and underlying aetiology of prolonged PR interval. Equally, the effects of potential confounding factors may vary across the studies because of these differences. Collectively, these factors are likely contribute to clinical heterogeneity in effect sizes. In addition, we note that the participants in the currently pooled studies are of different design with different inclusion criteria. This form of methodological heterogeneity among the studies may account for different results in each study. Therefore it is possible that for some populations, prolonged PR interval may be 
a benign finding. Our study has a number of strengths and limitations. We included over 400,000 subjects from 12 studies. We were able to consider the effects of adjustments including the impact of adjustments for medications and cardiovascular disease. Furthermore, we evaluated a variety of clinically relevant cardiovascular outcomes. All of the included studies are all observational in nature. For some cardiovascular events follow up, the outcome ascertainment is less reliable but mortality events are easily ascertained. This is a problem for outcomes that may be asymptomatic such as atrial fibrillation especially in studies that use hospitalization data. We also observed either a lack of description of the leads use for evaluation of PR interval or inconsistencies in choice of leads for evaluation for heart block among the included studies. We were also unable to determine if prolongation of PR interval was persistent among the studies. Additional limitations include the lack of trending data with regards to the degree of PR-interval and risk of adverse outcomes. Furthermore, an important consideration is use of pharmacological agents which could impact PR prolongation. We found that 8 studies adjusted for medications as potential confounders and 1 study excluded patients on nodal-blocking medications while 6 studies did not consider the effects of medications. There are also limitations because end points have been defined and measured in different ways and at different time points amongst the studies.

\section{Conclusions}

In a relatively, unselected population of patients in this meta-analysis, PR interval prolongation might be associated with adverse cardiovascular events and mortality but further studies are needed. Future studies should also focus on providing mechanistic insight and define the optimal monitoring strategy for such patients. 
Acknowledgements: None.

Funding: None.

Competing Interests: None. 


\section{References}

1. Bexton RS, Camm AJ. First degree atrioventricular block. Eur Heart J. 1984;5 Suppl A:107-9.

2. Mymin D, Mathewson FA, Tate RB, et al. The natural history of primary first-degree atrioventricular heart block. $N$ Engl J Med. 1986;315:1183-7.

3. Perlman LV, Ostrander LD, Keller JB, et al. An epidemiologic study of first degree atrioventricular block in Tecumseh, Michigan. Chest. 1971;59:40-46.

4. Aro AL, Anttonen O, Kerola T, et al. Prognostic significance of prolonged PR interval in the general population. Eur Heart J. 2014;35:123-129.

5. Heart Block. Available at: http://www.nhs.uk/Conditions/Heartblock/Pages/Introduction.aspx. Accessed October 31, 2015.

6. Heart Block. Available at: http://my.clevelandclinic.org/services/heart/disorders/arrhythmia/heart-block. Accessed October 31, 2015.

7. Atrioventricular block. Available at: http://www.merckmanuals.com/professional/cardiovascular-disorders/arrhythmiasand-conduction-disorders/atrioventricular-block. Accessed October 31, 2015.

8. Epstein AE, DiMarco AE, Ellebogen KA, et al. ACC/AHA/HRS 2008 Guidelines for device-based therapy for cardiac rhythm abnormalities. Circulation. 2008;117:e350e408.

9. Brignole M, Auricchio A, Baron-Esquivias G, et al. 2013 ESC Guidelines on cardiac pacing and cardiac resynchronization therapy. Eur Heart J. 2013;34:2281-2329.

10. Erikssen J, Otterstad JE. Natural course of a prolonged PR interval and the relation between PR and incidence of coronary heart disease. A 7-year follow-up study of 1832 apparently health men age 40-59 years. Clin Cardiol. 1984;7:6-13.

11. Rajala S, Haavisto M, Kaltiala K, et al. ECG findings and survival in very old people. Eur Heart J. 1985;6:247-252.

12. Cheng S, Keyes MJ, Larson MG, et al. Long-term outcomes in individuals with prolonged PR interval or first-degree atrioventricular block. JAMA. 2009;301:25712577.

13. Nielsen JB, Pietersen A, Graff C, et al. Risk of atrial fibrillation as a function of electrocardiographic PR interval: Results from the Copenhagen ECG study. Heart Rhythm. 2013;10:1249-1256.

14. Perez MV, Dewey FE, Marcus R, et al. Electrocardiographic predictors of atrial fibrillation. Am Heart J. 2009;158:622-8.

15. Soliman EZ. Prineas RJ, Case D, Zhang Z, Goff DC. Ethnic distribution of ECG predictors of atrial fibrillation and its impact of understanding the ethnic distribution of ischemic stroke in the Atherosclerosis Risk in Communities Study. Stroke. 2009;40:1204-1211.

16. Uhm JS, Shim J, Wi J, et al. First-degree atrioventricular block is associated with advanced atrioventricular block, atrial fibrillation and left ventricular dysfunction in patients with hypertension. J Hypertension. 2014;32:1115-1120. 
17. Hismatsu T, Miura K, Fujiyoshi A, et al. Long-term outcomes associated with prolonged PR interval in the general Japanese population. Int J Cardiol. 2015;184:291-293.

18. Cheng M, Lu X, Huang J, et al. Electrocardiographic PR prolongation and atrial fibrillation risk. J Cardiovasc Electrophysiol. 2015;26:36-41.

19. Ioannidis JP, Trikalinos TA. The appropriateness of asymmetry tests for publication bias in meta-analyses: a large survey. CMAJ. 2007;176:1091-6.

20. Crisel RK, Farzaneh-Far R, Na B, et al. First-degree atrioventricular block is associated with heart failure and death in persons with stables coronary artery disease: data from the Heart and Soul Study. Eur Heart J. 2011;32:1875-1880.

21. Knuiman M, Briffa T, Bivitini M, et al. A cohort study examination of established and emerging risk factors for atrial fibrillation: the Busselton Health Study. Eur J Epidemiol. 2014;29:181-90.

22. Kobayashi T, Watanabe M, Kokubo Y, Kamakura S, Kusano K, Miyamato Y. Prolonged PR interval is significantly associated with increased risk of cardiovascular diseases and stroke in a population-based cohort study. Circulation. 2014;130:A13451.

23. Magnani JW, Wang N, Nelson KP, et al. Electrographic PR interval and adverse outcomes in older adults. Circ Arrhythm Electrophysiol. 2013;6:84-90.

24. Soliman EZ, Cammarata M, Li Y. Explaining the inconsistent associations of PR interval with mortality: The role of P-duration contribution to the length of PR interval. Heart Rhythm. 2014;11;93-98.

25. Brown RW, Hunt D, Sloman JG. The natural history of atrioventricular conduction defects in acute myocardial infarction. Am Heart J. 1969;78:460-466.

26. Waller B. Anatomy, histology and pathology of the cardiac conduction system-Part V. Clin Cardiol. 1993;16:565-569.

27. de Jong S, van Veen TAB, van Rijen HVM, de Bakker JMT. Fibrosis and cardiac arrhythmias. J Cardiovasc Pharmacol. 2011;57:630-638.

28. Kistler PM, Sanders P, Fynn SP, et al. Electrophysiologic and electroanatomic changes in the human atrium associated with age. J Am Coll Cardiol. 2004;44:109-16.

29. Kojodjojo P, Kanagaratnam P, Markides V, et al. Age-related changes in human left and right atrial conduction. J Cardiovasc Electrophyiol. 2006;17:120-7.

30. Kitchin AH, Milne JS. Longitudinal survey of ischaemic heart disease in randomly selected sample of older population. Br Heart J. 1997;39:889-893.

31. Rose G, Baxter PJ, Reid DD, McCartney P. Prevalence and prognosis of electrocardiographic findings in middle-aged men. Br Heart J. 1978;40:636-643.

32. Ostor E, Schnohr P, Jensen G, Nyboe J, Hansen AT. Electrocardiographic findings and their association with mortality in the Copenhagen City Heart Study. Eur Heart J. 1981;2:317-28.

33. The Fifth Joint Task Force of European Society of Cardiology and Other Societies on Cardiovascular Disease Prevention in Clinical Practice. European Guidelines on cardiovascular disease prevention in clinical practice (version 2012). Eur Heart J. 2012;33:1635-1701. 


\section{List of Tables and Figures}

Table 1: Study design and participant characteristics

Table 2: Outcomes evaluated and results

Table 3: Summary of meta-analysis results 